\title{
Damage and Ground Motion of the 26 December 2006 Pingtung Earthquakes, Taiwan
}

\author{
Kou-Liang Wen ${ }^{1,2,3, *}$, Yu-Wen Chang ${ }^{2}$, Che-Min Lin ${ }^{1}$, \\ Hsien-Jen Chiang ${ }^{1}$, and Ming-Wey Huang ${ }^{3}$ \\ ${ }^{1}$ Institute of Geophysics, National Central University, Chung-Li, Taiwan, ROC \\ ${ }^{2}$ National Center for Research on Earthquake Engineering, National Applied Research Laboratories, Taipei, Taiwan, ROC \\ ${ }^{3}$ National S\&T Center for Disaster Reduction, National Applied Research Laboratories, Taipei, Taiwan, ROC
}

Received 7 January 2008, accepted 26 September 2008

\begin{abstract}
Two consecutive large earthquakes eight minutes apart occurred offshore of Hengchun, Pingtung County of Taiwan at night on 26 December 2006. The seismic intensity in the Kaohsiung and Pingtung areas reached 5 according to the Central Weather Bureau's intensity scale making them the strongest earthquakes in the Hengchun area in a century. These earthquakes were felt throughout Taiwan. Because the earthquakes were located not far offshore, seismic instruments at the Taipower's Nuclear Power Plant No. 3 (NPP3) registered their largest motions since recording commenced at the site. As a result, unit 2 of NPP3 was shut down while Unit 1 remained operating at full capacity. Other damage that occurred during the Earthquake Doublet included building collapse, rock falls, structure and non-structural damage to buildings, fire, and damage to utilities such as gas, electricity, and telephone lines; liquefaction was also noted. In this paper, the shakemaps based on the source parameters and real-time observations were predicted and compared with the recorded shakemaps. This analysis shows our shakemap prediction model to be extremely useful in predicting what emergency response units can expect after a large damaging earthquake. Strong motion data near a collapsed building was used to calculate the response spectrum and compared with the building codes to check the reason of the building collapsed. This study presents the damage that occurred during this event and the results of the seismic assessment to discuss why so much damage occurred in the southern Taiwan area.
\end{abstract}

Key words: Shakemap, Response spectrum, Building code

Citation: Wen, K. L., Y. W. Chang, C. M. Lin, H. J. Chiang, and M. W. Huang, 2008: Damage and ground motion of the 26 December 2006 Pingtung earthquakes, Taiwan. Terr. Atmos. Ocean. Sci., 19, 641-651, doi: 10.3319/TAO.2008.19.6.641(PT)

\section{INTRODUCTION}

A $\mathrm{M}_{\mathrm{L}}$ 7.0 earthquake took place at 20:26:21.0 (Taiwan local time, the event is thus referred to as the 2026 Earthquake) on 26 December 2006 at about $38.4 \mathrm{~km}$ southwest of Kenting. The epicenter was located in the offshore area (Fig. 1a). About eight minutes later at 20:34:15.1 (referred to as the 2034 Earthquake) another strong $\mathrm{M}_{\mathrm{L}} 7.0$ shock occurred (Fig. 1b). The epicenter of the first shock was located at $21.69^{\circ} \mathrm{N}$ and $120.56^{\circ} \mathrm{E}$. Its focal depth was $44.1 \mathrm{~km}$. The 2034 Earthquake, at a depth of $50.2 \mathrm{~km}$, was located at $21.97^{\circ} \mathrm{N}$ and $120.42^{\circ} \mathrm{E}$. Both were felt over a wide area. The Seismology Center of the Central Weather Bureau (CWB) stated that according to its records there has never been such

\footnotetext{
* Corresponding author

E-mail:wenkl@earth.ncu.edu.tw
}

a large earthquake within $50 \mathrm{~km}$ of the epicenter. The Earthquake Doublet took place in an area where the Eurasian and Philippine Sea plates interact. The Philippine Sea plate subducts northward under the Eurasian plate after their collision along the eastern offshore areas of Taiwan. Meanwhile, in the southwestern offshore areas, the Eurasian plate begins to subduct eastward under the Philippine Sea plate (Tsai et al. 1977; Wu 1978; Lin 2002). The latest earthquakes happened to occur in this area. Many aftershocks took place following the main shock. Up to 13:00 of December 27, 132 aftershocks has been recorded, among them nine were in the range $\mathrm{M}_{\mathrm{L}} 4.7$ to 6.4. Most had focal depths less than $30 \mathrm{~km}$. Figure 2 shows the epicenters of the main shock and larger aftershocks.

We conducted a field survey after the earthquakes and in 
(a)

2006 Pingtung Earthquake

Local Time=20:26:21.0 Position=120.56E/21.69N $\mathrm{ML}=7.0$ Depth $=44.1 \mathrm{~km}$

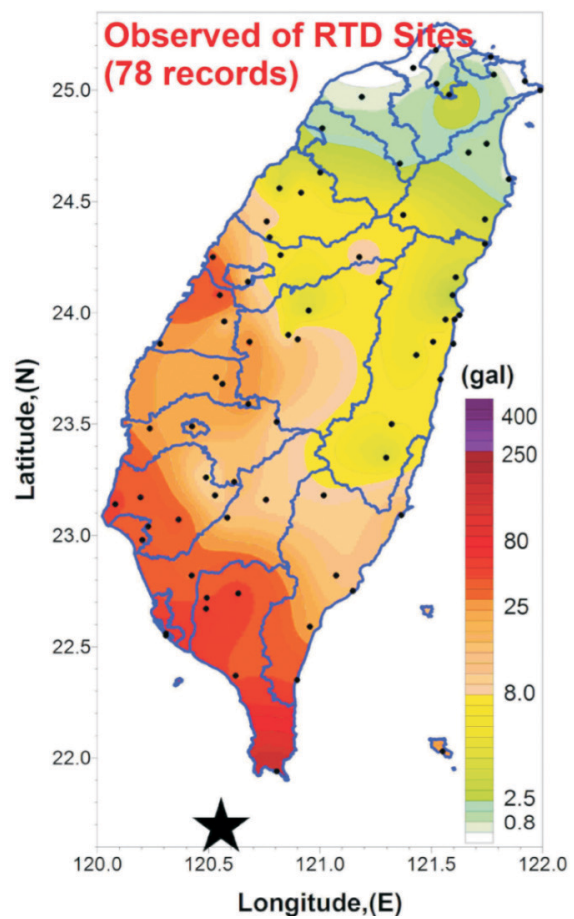

(b)

2006 Pingtung Earthquake

Local Time=20:34:15.1

Position=120.42E/21.97N

$M L=7.0$ Depth $=50.2 \mathrm{~km}$

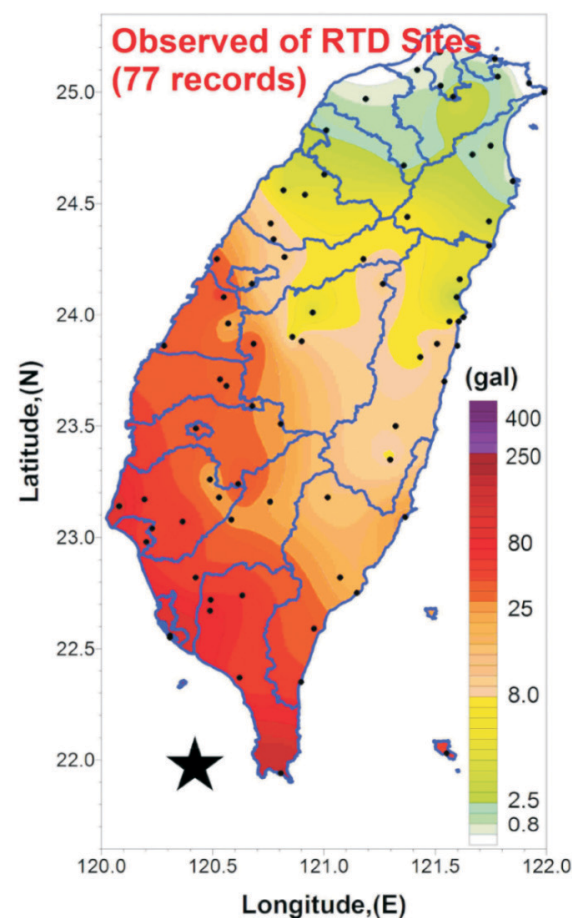

Fig. 1. Rapid report of the 26 December 2006 Pingtung Doublet Earthquake by the Central Weather Bureau. (a) 2026 Earthquake; (b) 2034 Earthquake.

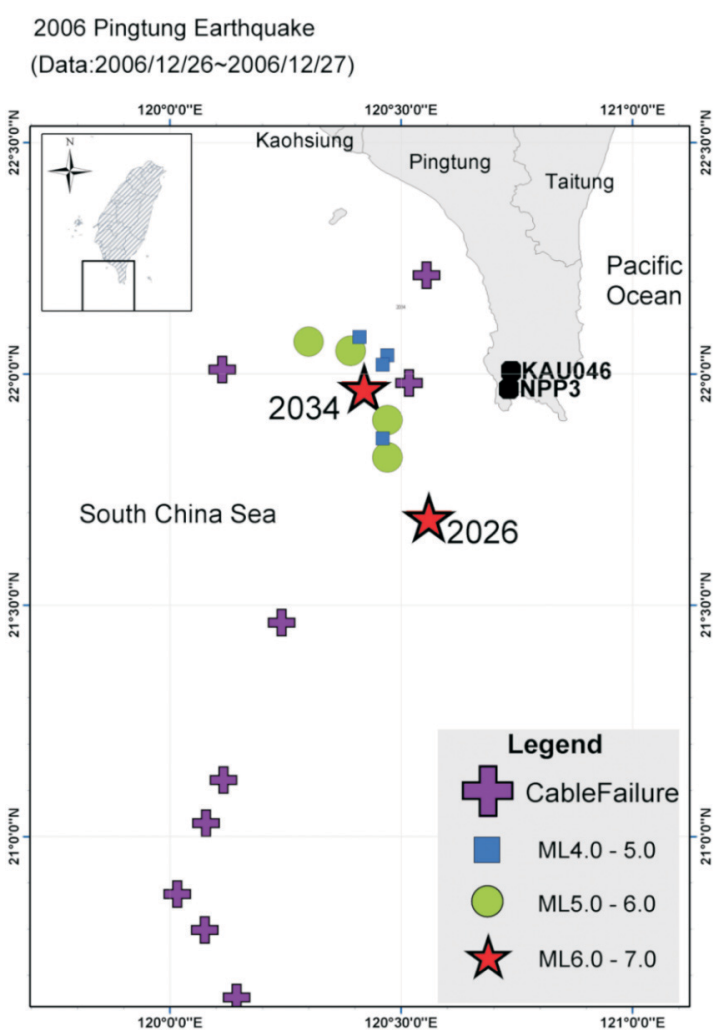

Fig. 2. Epicenters of the Earthquake Doublet of 26 December 2006 and its aftershocks. Cable failures also marked by crosses. this paper we report the damage and analyze collected ground motion recordings of the Taiwan Strong Motion Instrumentation Program (TSMIP network: Kuo et al. 1995; Liu et al. 1999) operated by the Central Weather Bureau. We use this data to compare peak ground accelerations (PGAs) and the response spectra with the building codes to better understand the reasons why such extensive damage occurred.

\section{REGIONAL GEOLOGY AND BACKGROUND SEISMICITY}

\subsection{Regional Geology}

The hills on the east side of Hengchun Peninsula are the southern extension of the Central Mountains Range. Their strikes are mostly in a north- or northeast-south direction. Major rivers on the slopes facing east include Kangkou and Chioupeng creeks, both of which flow into the Pacific Ocean. Those on the slopes facing west include the Suchung, Baoli, and Wangsha creeks; all of these flow into the South China Sea. Several well-developed terraces are cut by these creeks. The coast of the Hengchun Peninsula is surrounded by coral reefs. Sand dunes and beaches are common. A narrow, low-lying valley running from north to south from Haikou to Nanwan is the most exceptional topographic feature. Along the valley's eastern flank are hills and high- 
lands of varying elevations. Along its western flank are undulating plains with elevations between 5 and 100 meters.

Ho (1986) considered the Hengchun Peninsula as a very narrow section of the southernmost Central Mountain Range, forming the southernmost tip of Taiwan Island. The region is mainly composed of sedimentary sequence of Miocene for- mations. On top of these Miocene formations are partially covered Pliocene-Pleistocene and more recent sediments (Fig. 3). In terms of stratigraphy, the northern part of Hengchun Peninsula is composed of slightly metamorphosed argillites and slates, interspersed with small amounts of sandstones. These rocks are considered part of the Lushan For-

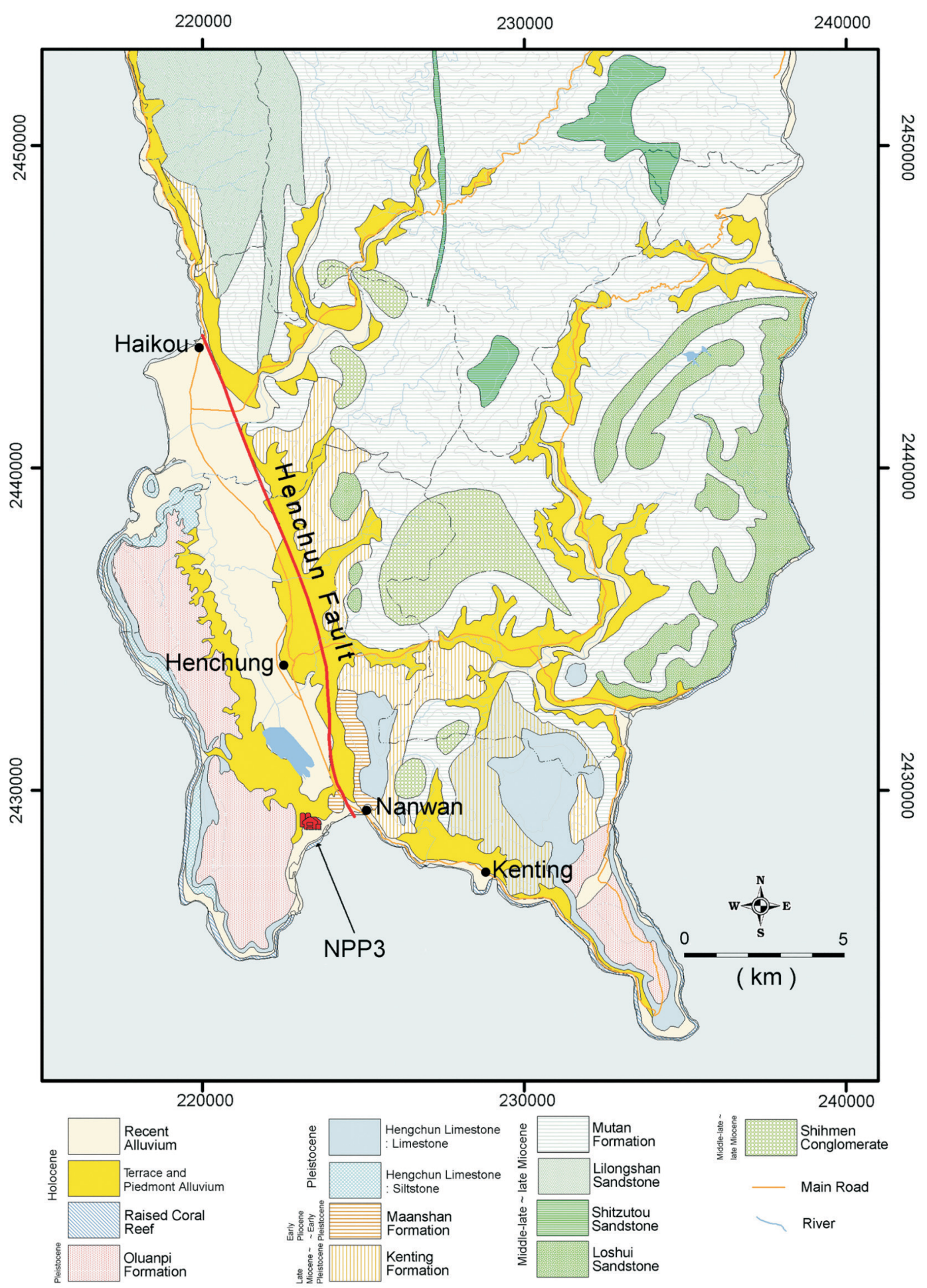

Fig. 3. Geologic map of southern Taiwan (modified from Central Geological Survey). 
mation. The southern part of the Hengchun Peninsula is mainly composed of Tertiary sediments, transitioning northward into the Lushan Formation. Tsan (1974a, b) in his geological surveys of this area named the lower part of the Miocene Formation as Changlo Formation, mostly consisting of dark gray shale. He named the upper layer as Loshui Formation, consisting of sandstone and shale, with some conglomerates. Pelletier and Stephan (1986) lumped together all Miocene rocks as the Suchunghsi Formation, including the Kenting melanges.

The Maanshan Formation is a west dipping monocline. Its dip angle averages about $45^{\circ}$, although it varies locally. These Pliocene-Pleistocene sediments are in unconformity with the Miocene formations on the east side of the NPP3 plant site. Many researchers inferred this boundary as a major fault structure (i.e., the so called Hengchun Fault). Regarding tectonic activities, it is generally agreed that available evidence for fault movements is confined to the Miocene formation. The fault movements are considered to be related to a regional stress field at the time. Available evidence suggests that the Hengchun Peninsula has not been subjected to major fault movements since the late Pliocene to early Pleistocene. Early researchers on the geology of the Hengchun Peninsula proposed the Hengchun Fault to be a major NS striking fault on the west side of the Peninsula. It is located along the contact zone between the Pliocene-Pleistocene sedimentary rocks on the west and the Miocene rocks on the east. It is generally considered now to be a fault which lacks evidence of recent activity.

Although the Hengchun Fault in southernmost Taiwan is marked by an apparent topographical lineament on land (Fig. 3), its offshore extension is not obvious. This is probably because the area is in an ongoing sedimentation environment. Regardless, the sea floor topography still shows a linear depression down to about $21^{\circ} 50^{\prime}$, where it is cut by an EW submarine channel. Whatever the case, it is still hard to trace the offshore extension of Hengchun Fault with currently available data.

\subsection{Background Seismicity}

Monitoring of regional seismicity in Taiwan has been significantly improved since 1990 after the CWB installed dense networks of strong motion accelerographs and realtime seismic stations with high-gain velocity sensors. Figure 4 shows a map of earthquake epicenters in southern Taiwan area from 1900 to Oct. 2006. In the figure the size of dots represents magnitude, whereas the color represents focal depth (h): red for $\mathrm{h}<20 \mathrm{~km}$, green for $50>\mathrm{h}>$ $20 \mathrm{~km}$, and blue for $\mathrm{h}>50 \mathrm{~km}$. We can see clearly from the figure that most earthquakes occurred along the east coast and its offshore areas. There are significant earthquake activities under Taiwan Island due to collision of the Phil- ippine Sea and Eurasian plates (Tsai et al. 1977; Wu 1978; Lin 2002). It is evident from the figure that Hengchun area has relatively low seismicity as compared to other areas in Taiwan.

\section{DAMAGE CAUSED BY THE PINGTUNG EARTHQUAKE}

According to the field survey after the Earthquake Doublet, three residential houses collapsed, and numerous others suffered cracks in their walls in the Hengchun area. Some fence walls collapsed. Ceilings in many old houses as well as in the Pingtung County Government Office fell leaving a mess on the floor. A road next to the Shanhai Elementary School failed, resulting in piles of debris in the playground. Some classrooms suffered severe cracking and peeling on the walls. Some cracks extended for as long as 10 meters. Figure 5 shows some photos of building damage. Rock falls in the Shanhai Elementary School are shown in Fig. 6. In the Nanwan area two locations exhibited liquefaction, though this was due to the lack of compaction of the back-fill soil not the original soil layer (Fig. 7).

Fires broke out at two stores in a shopping mall on Chungcheng Road in the old district of Hengchun. Figure 8 shows an example of how the fire occurred and the extent of fire damage. Two feeder lines between Pingtung and Chehcheng were broken, resulting in power outages for about 3000 customers. Gas leaked in a cooking classroom of the Hengchun Vocational School. Unit 2 of Taipower's NPP3 was manually shut down and safety valves were tripped at the Taling Oil Refinery in Kaohsiung. In addition, fires broke out at two houses in Nantzu District of Kaohsiung. In twelve cases people were being trapped in elevators and in one case of a gas leak were reported. The earthquakes also caused major failures of submarine fiber-optic communication cables in the offshore areas of Hengchun (Fig. 2), disrupting international telephone and Internet connections (Hsu and MACHO Working Group 2007).

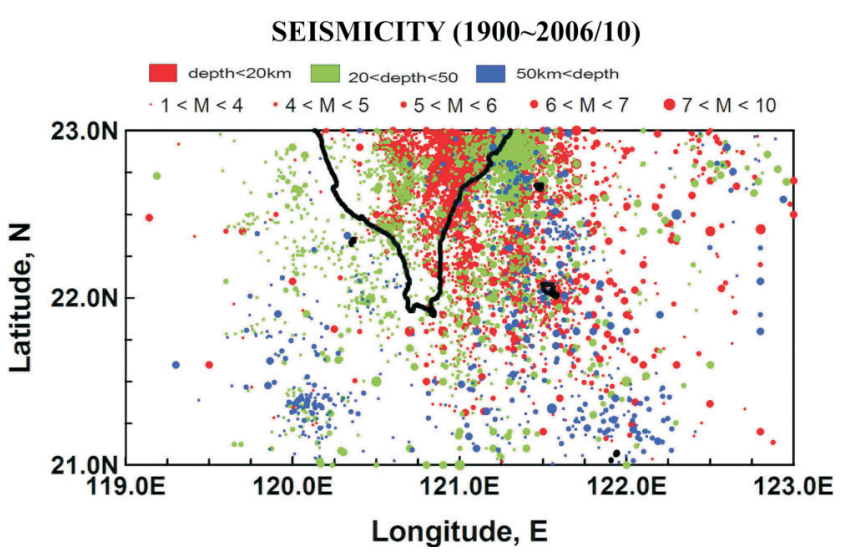

Fig. 4. Seismicity map of Taiwan (1900 - Oct. 2006). 

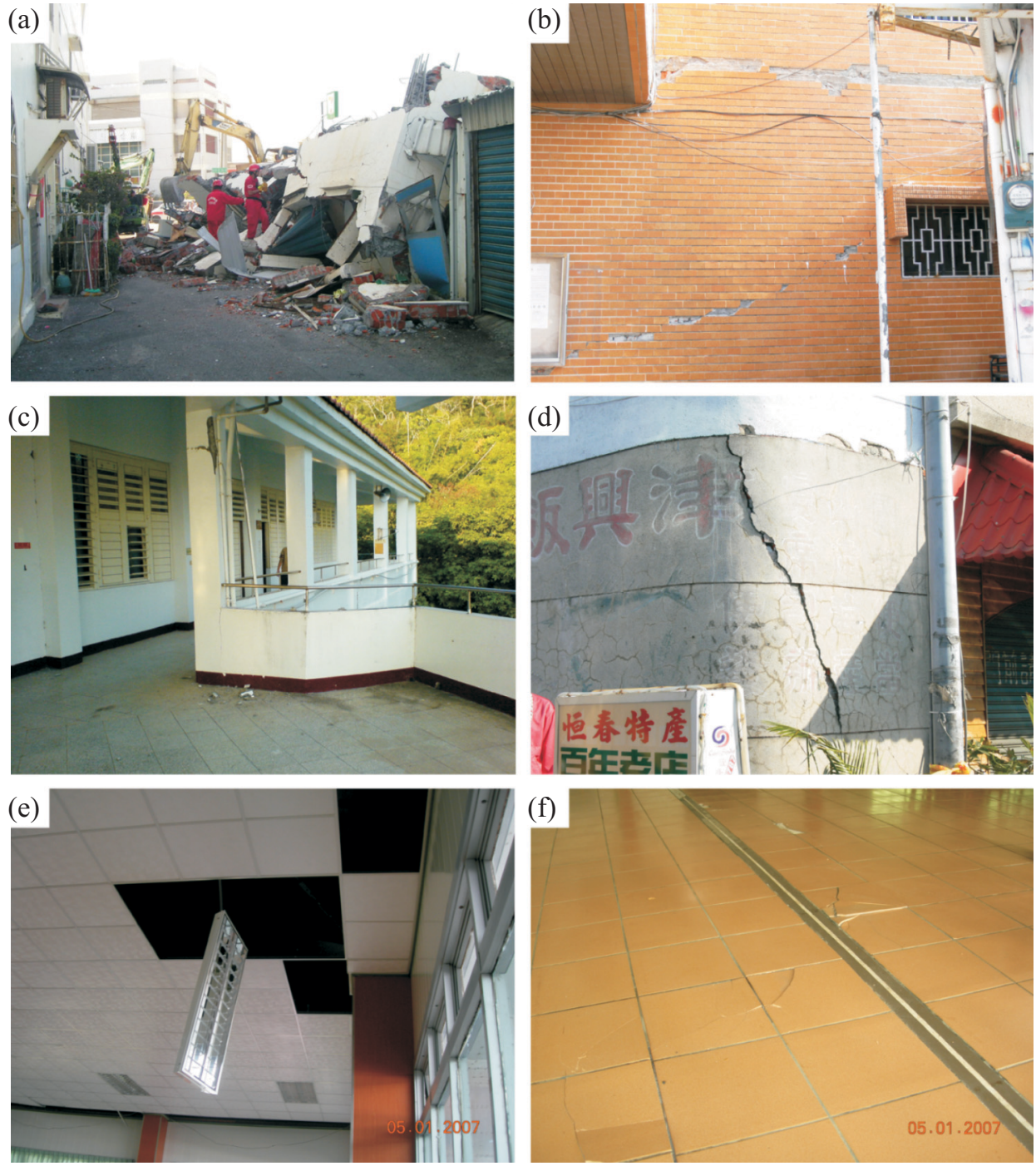

Fig. 5. (a) Building collapsed in the Hengchun area. (b) A shared cracked wall in the Hengchun area. (c) Column damage in the Hengchun area. (d) Structural damage in the Hengchun area. (e) Non-structural damage in the Nanwan area. (f) Non-structural damage in the Nanwan area.
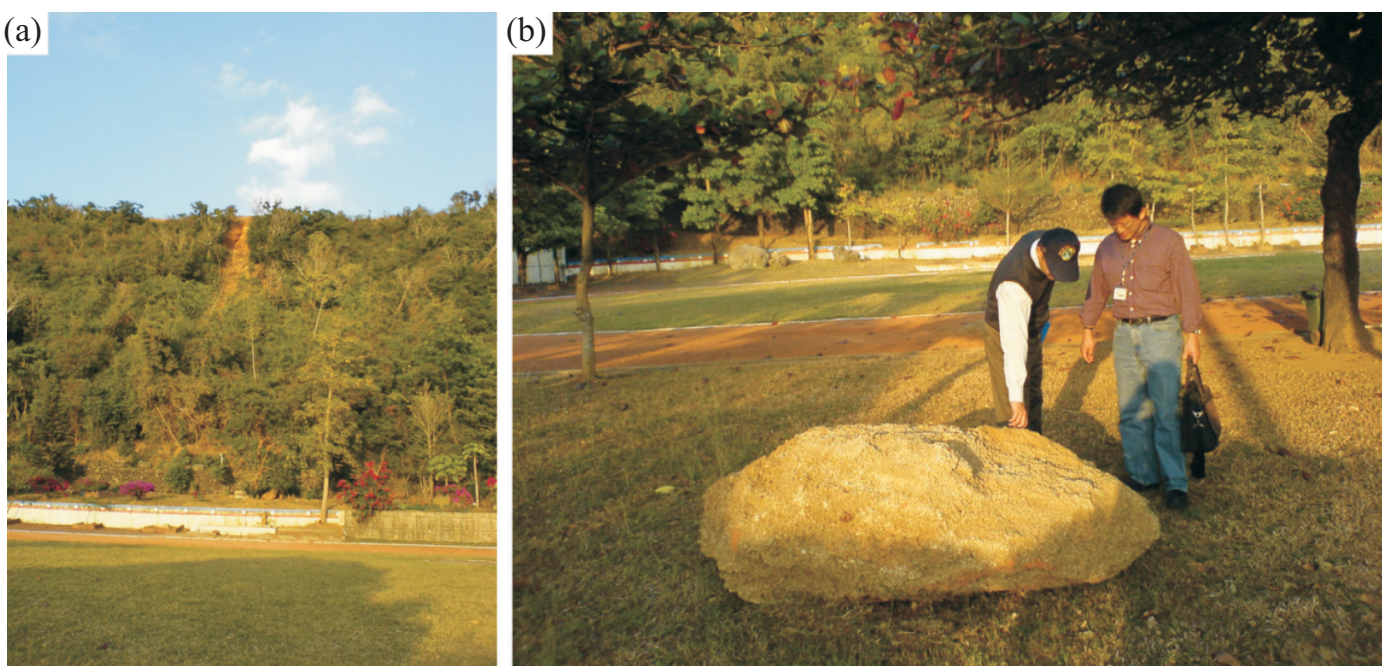

Fig. 6. (a) Rock fall from the small hill to playground of an elementary school. (b) Rock fall in an elementary school. 

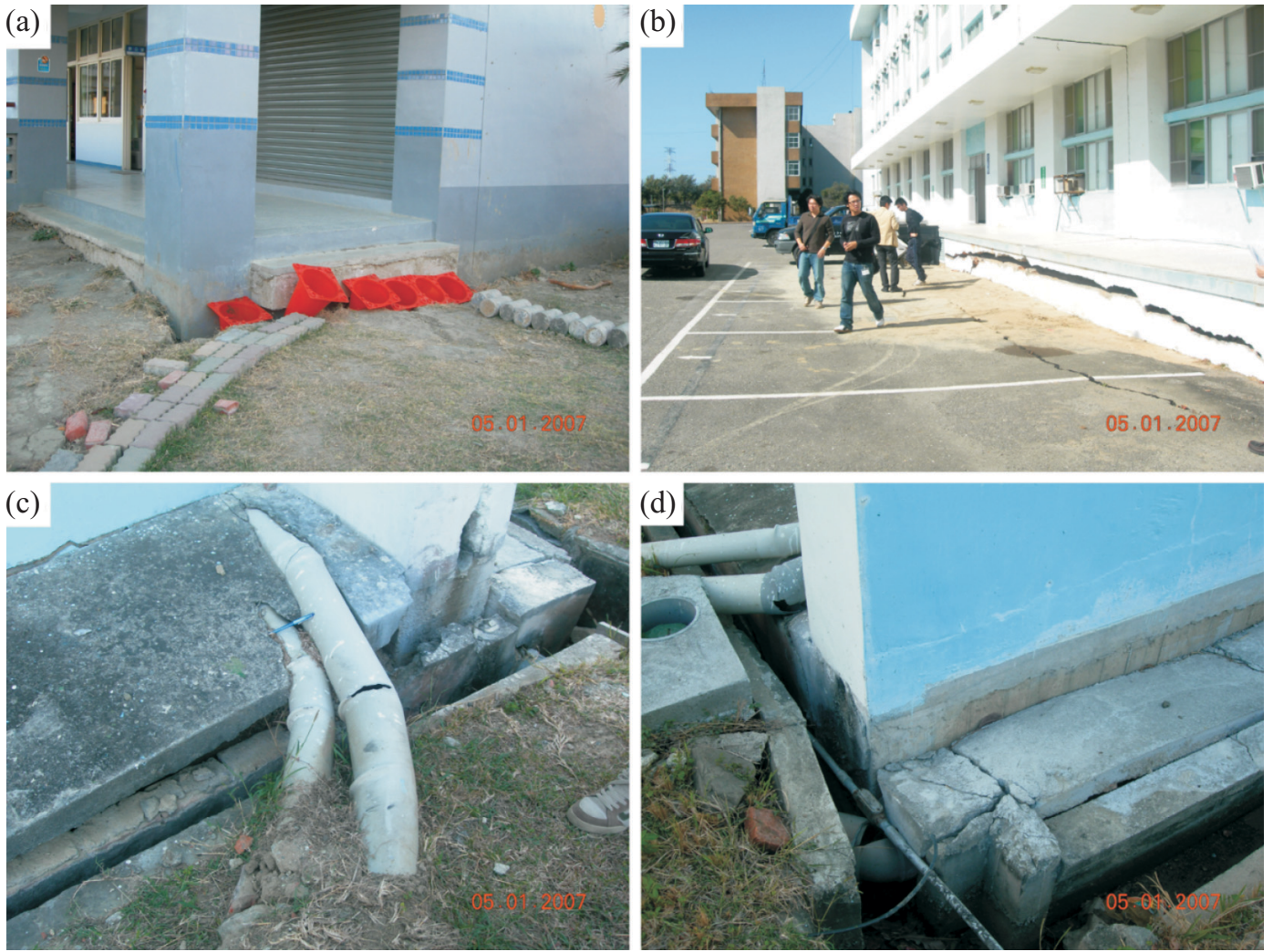

Fig. 7. (a) Liquefaction in the Nanwan elementary school. (b) Liquefaction in the Nanwan area. (c) Pipeline damage due to the liquefaction. (d) Subsidence due to the liquefaction.
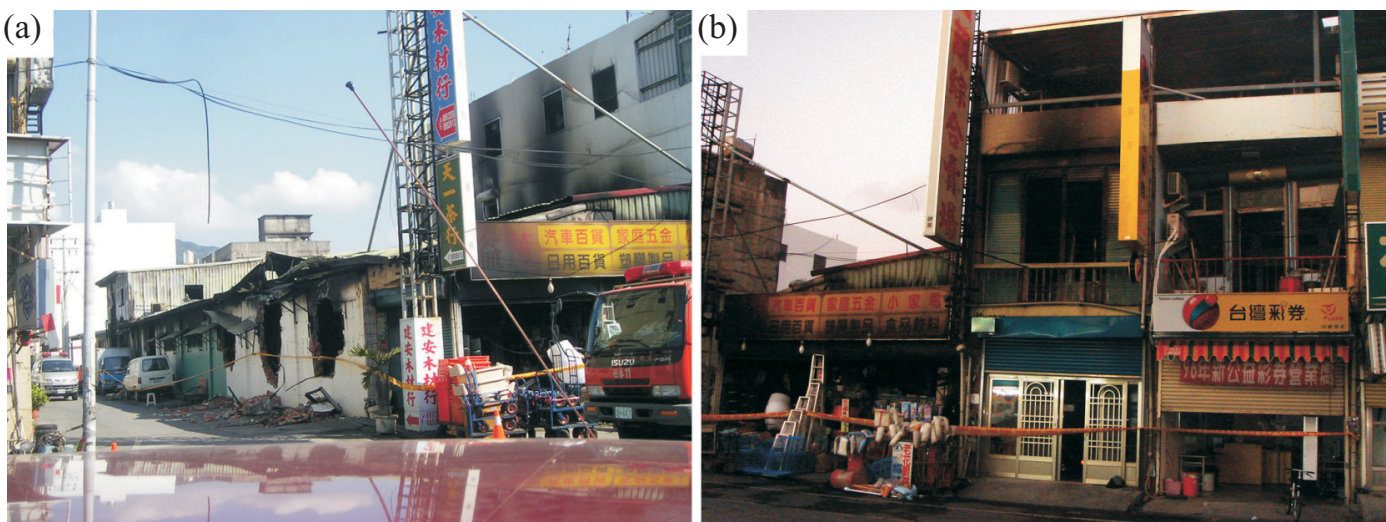

Fig. 8. (a) Fire in the Hengchun area. (b) Fire extending to a neighboring building.

\section{STRONG MOTION ANALYSIS}

\subsection{Analysis of Peak Acceleration Values}

Depending on rock properties and geometric spreading of seismic wave propagation paths, the shaking intensity (in terms of PGA for example) attenuates with distance. In engineering applications the attenuation of seismic intensity can be expressed as:

$Y=f(M, R)$ where $M$ and $R$ represent earthquake magnitude and source distance, respectively. In practice, several functional forms are often used to represent attenuation. In this study, we adopt Campbell's form (Campbell 1981) for regression as follows:

$Y=f(M, R)=a_{1} e^{a_{2} M}\left[R+a_{4} \exp \left(a_{5} M\right)\right]^{-a_{3}}$

Table 1 gives the regression values of parameters $a_{1}$ to $a_{5}$ for PGA, $\mathrm{S}_{\text {as }}$, and $\mathrm{S}_{\mathrm{al}}$ (short- and long-period spectral ac- 
Table 1. Coefficients and standard deviations of the attenuation relations for rock sites in Taiwan (Jean 2001; Jean et al. 2003).

\begin{tabular}{ccccccc}
\hline Att. Form & $\boldsymbol{a}_{\boldsymbol{1}}$ & $\boldsymbol{a}_{2}$ & $\boldsymbol{a}_{3}$ & $\boldsymbol{a}_{4}$ & $\boldsymbol{a}_{5}$ & $\sigma_{\text {InErr }}$ \\
\hline PGA & 0.00369 & 1.75377 & 2.05644 & 0.12220 & 0.78315 & 0.7564 \\
$\mathrm{~S}_{\mathrm{as}}$ & 0.00974 & 1.73484 & 2.08572 & 0.11365 & 0.80032 & 0.7468 \\
$\mathrm{~S}_{\mathrm{al}}$ & 0.00279 & 1.77305 & 2.04190 & 0.11542 & 0.77139 & 0.8560 \\
\hline
\end{tabular}

celerations), respectively (Jean 2001; Jean et al. 2003). The results for Table 1 are based on observed ground motion data (including the Chi-Chi earthquake and its aftershocks) from 1993 to 2000. The ground motion parameters are represented as the geometric mean of two orthogonal horizontal components. In regression analysis for the attenuation coefficients, we included all hard site stations except those in the Taipei Basin and Ilan Plain. Following typical seismic hazards analysis (Campbell 1981, 1997), the definition of closest distance to the fault is used for R. Thus, Equ. (2) can be used to assess seismic hazards in the Taiwan area.

By substitution in Equ. (2) with the magnitude and focal depth of the Earthquake Doublet and the coefficients in Table 1, we can calculate the expected PGA values. The results are shown in Fig. 9: the solid curve is for the mean values and the dashed curves for the plus- and minus-one-standarddeviation values. The crosses in the figure show the geomet- ric mean of horizontal PGA values recorded at the CWB real-time strong motion stations. From the figure we can see that most of the observed PGA values are within one standard deviation, but some exceed the expected range due to site amplification at the alluvium plain in the southern Taiwan. The maximum PGA occurred at the Station KAU046 reaching about $0.26 \mathrm{~g}$ (Fig. 10).

The predictive model for potential ground motions (Jean et al. 2003, 2006; Wen et al. 2006) is based on the attenuation relation for hard sites and takes into account the site conditions of individual strong motion stations. It can be used to calculate the expected PGA values with given magnitude and location of an earthquake. We first apply equation (2) to calculate the expected ground motion values by using the values listed in Table 1 for coefficients $a_{1}$ to $a_{5}$. Next we incorporate the site amplification coefficients $C_{0}$ and $C_{l}$ in Equ. (3) to obtain the corrected ground motion
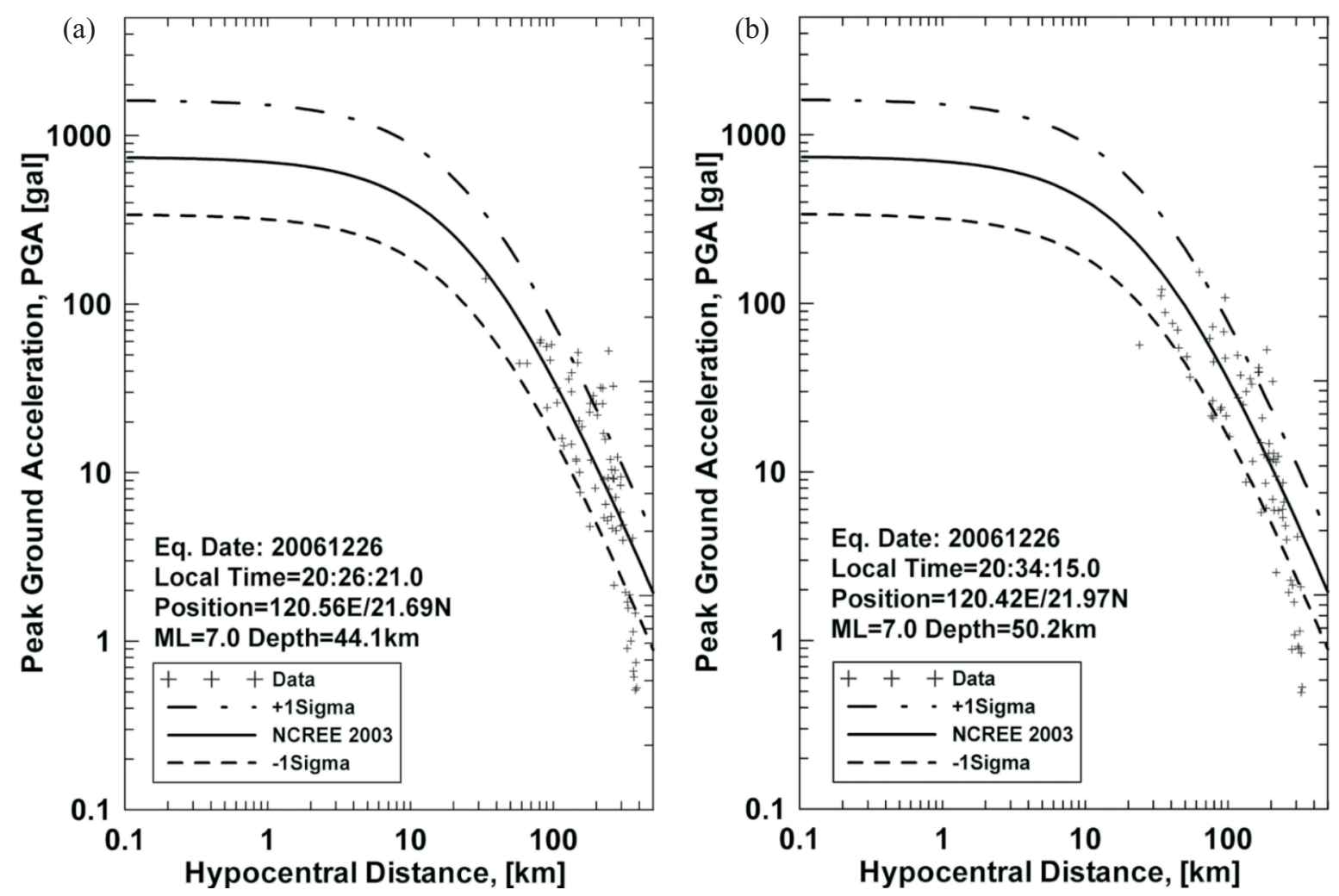

Fig. 9. PGA recorded at CWB real time stations and expected curve for the (a) 2026 earthquake and (b) 2034 earthquake. 


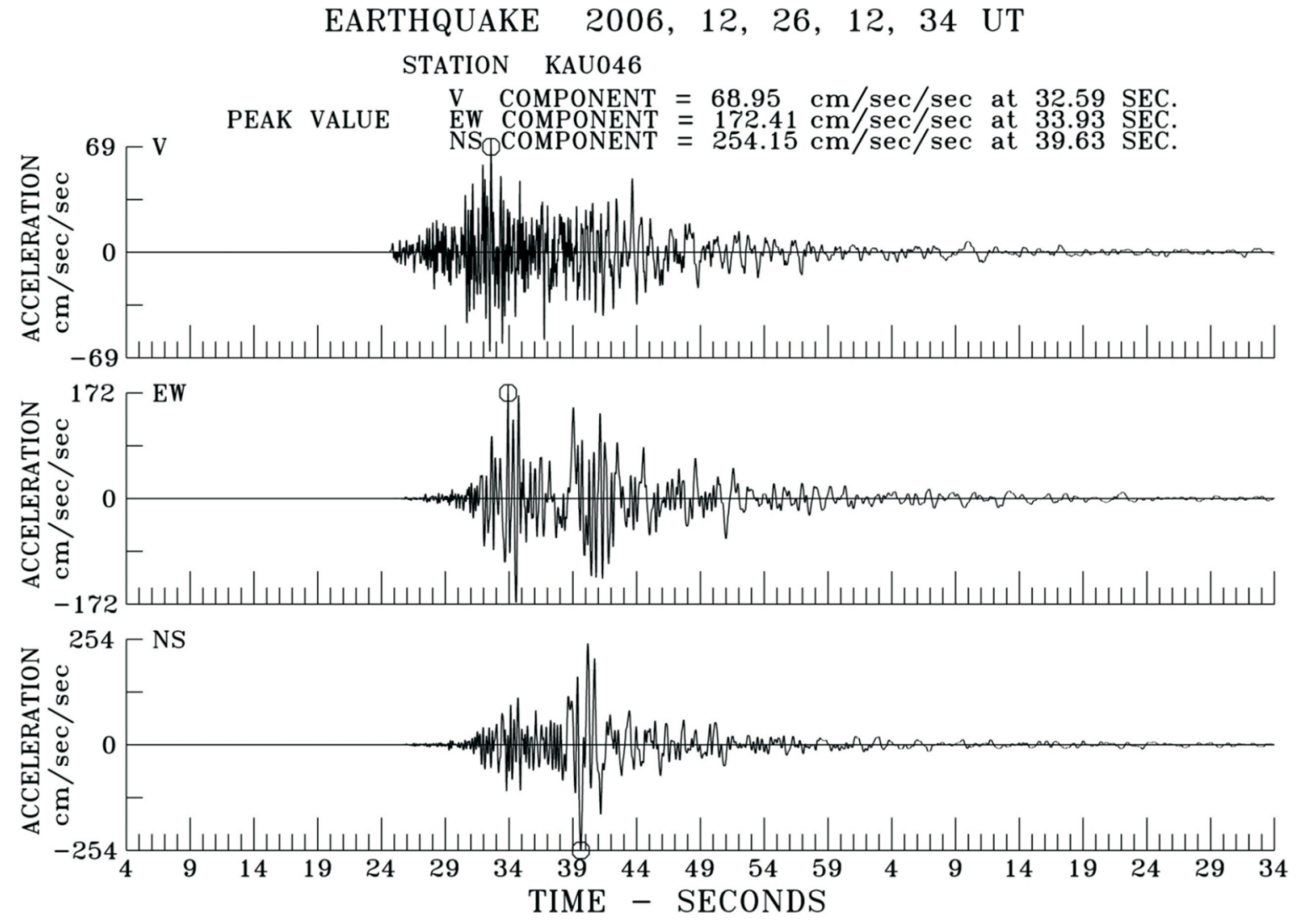

Fig. 10. Acceleration waveform of the 2034 Earthquake recorded at Station KAU046.

values at individual stations:

$\ln \left(Y_{e}\right)=C_{0}+C_{1} \times \ln (y)$

in which $y$ is calculated from Equ. (2), $C_{0}$ and $C_{I}$ are site amplification coefficients for each individual station, and $Y_{e}$ is the expected ground motion value after correction for local site effects. But the source characteristic was different for each earthquake, so the limited observations of the Real-Time Digital (RTD) stream output system can help to correct the source effect. The RTD system is capable of calculating the earthquake location and its magnitude about one minute after an earthquake occurs. The ground shaking information of the RTD site can also be automatically distributed at the same time (Jean et al. 2006). Using the expected ground motion values obtained by Equ. (3) and observations of the RTD system, we can construct shakemaps for potential earthquakes.

Taking the epicenter location, focal depth of $44.1 \mathrm{~km}$ and magnitude $M_{L} 7.0$ for the 2026 Earthquake, we use Equs. (2), (3), and observations of the RTD system to assess the probable ground motion distribution, as shown in Fig. 11a. It shows that the Hengchun area experienced CWB intensity 4. The results for the $M_{L} 7.02034$ Earthquake are shown in Fig. 11b. A relatively large area in
Pingtung suffered CWB intensity 5. These two expected ground motion maps show larger areas are greater than intensity 4 than those actually observed intensity values from the CWB real-time strong motion network shown in Fig. 1 for the Earthquake Doublet. After waiting several months to retrieve TSMIP records, the observation shakemaps of these two events were plotted in Fig. 12. The two expected ground motion maps are quite consistent with what were actually observed intensity values from the TSMIP strong motion network shown in Fig. 12. For the Pingtung area, the predicted PGA values seem a little higher than that of observed. But it still in the same Intensity scale. Due to the electric shutdown after the earthquake occurred, the data at Station KAU046 did not sent back to CWB. That's why Fig. 1 from RTD system only got maximum Intensity 4. So, RTD system can give us pretty good result immediately if the real time online communication system did not have problem. This shows that this predictive model for potential ground motions, which accounts for local site conditions, can reflect clearly the amplification effects of shaking intensity at soft soil sites. And this predictive model can be used immediately after we receive the earthquake source parameters, meaning this shakemap can be used as a reference for loss estimation and emergency response. 
(a) 2006 Pingtung Earthquake

Local Time $=20: 26: 21.0$ Position $=120.56 \mathrm{E} / 21.69 \mathrm{~N}$
$\mathrm{ML}=7.0$ Depth $=44.1 \mathrm{~km}$

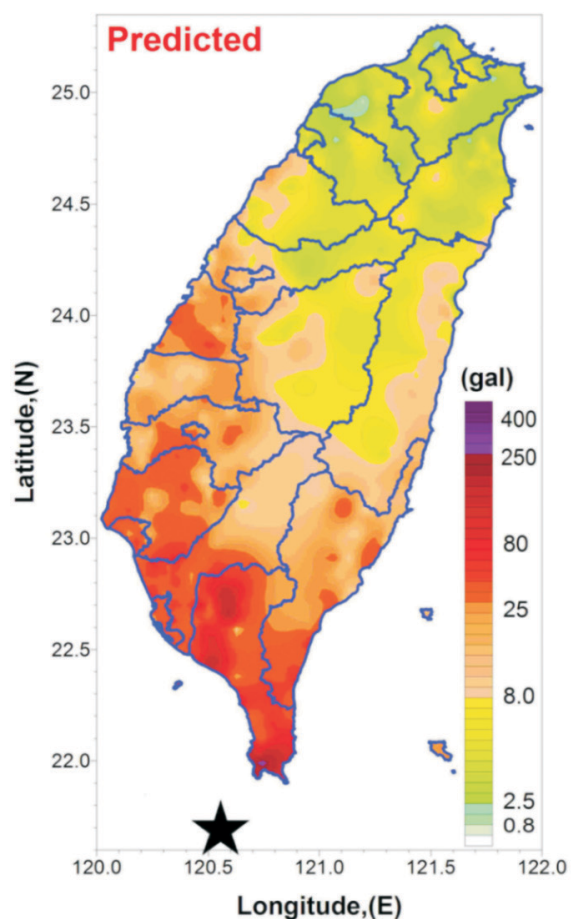

(b)

2006 Pingtung Earthquake

Local Time $=20: 34: 15.1$ Position=120.42E $/ 21.97 \mathrm{~N}$ $\mathrm{ML}=7.0$ Depth $=50.2 \mathrm{~km}$

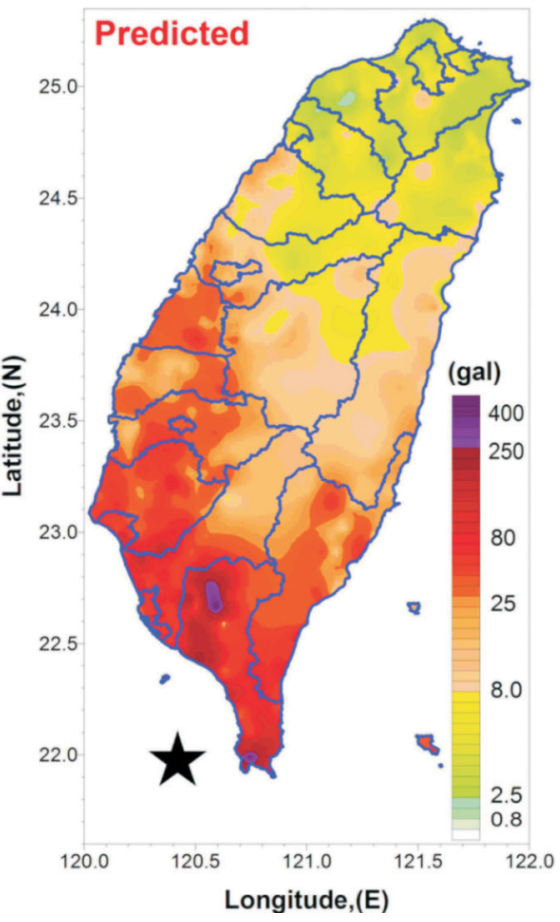

Fig. 11. Shakemap of expected PGA values for the (a) 2026 earthquake and (b) 2034 earthquake.

(a)

2006 Pingtung Earthquake

Local Time $=20: 26: 21.0$

Position=120.56E/21.69N

$M L=7.0$ Depth $=44.1 \mathrm{~km}$

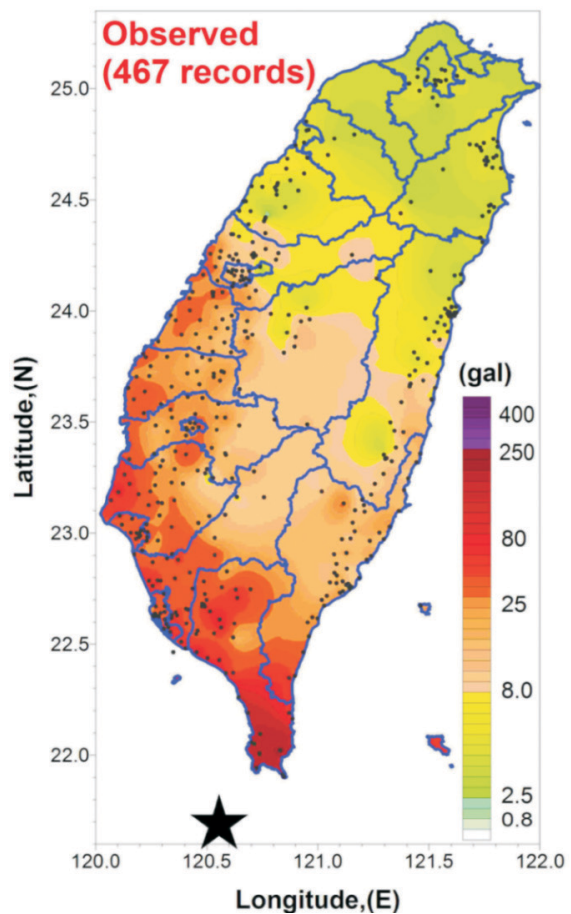

(b) 2006 Pingtung Earthquake

Local Time $=20: 34: 15.1$

Position=120.42E/21.97 N

$M L=7.0$ Depth $=50.2 \mathrm{~km}$

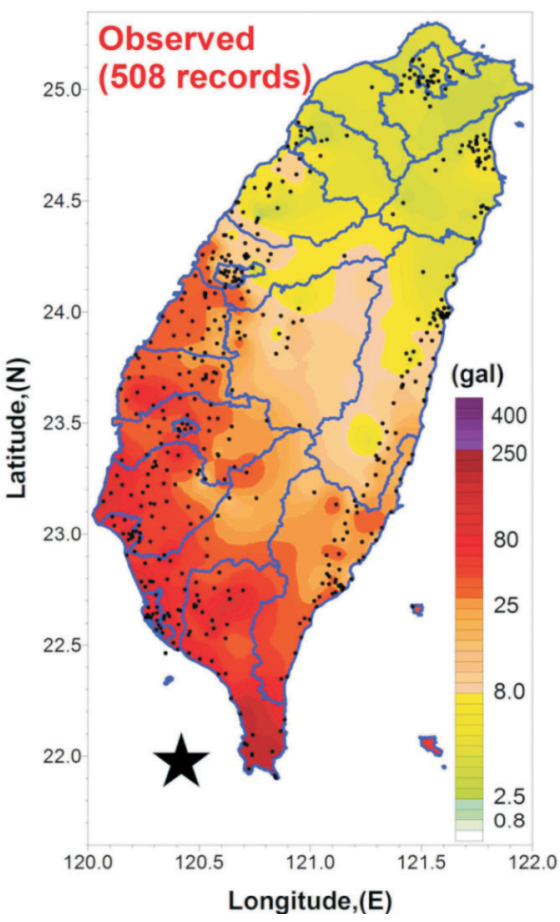

Fig. 12. Shakemap of observed PGA values for the (a) 2026 earthquake and (b) 2034 earthquake. 


\subsection{Analysis of Response Spectra}

During this earthquake, most of the buildings, collapsed or were damaged, were in the Hengchun area. On the basis of the building codes, the design spectra parameters in the Hengchun, Pingtung area for class 2 sites are listed in Table 2 (The Committee for Architecture Technique, 2005). For many buildings that are not newly constructed, structures need to conform the zoning parameter of $0.28 \mathrm{~g}$ (The Committee for Architecture Technique, 1995) in their design. The design code of code' 1995 and code'2005 in 2500 years return period are similar design PGA value. It means the design code in 1995 year was considering high safety factor. The maximum PGA value recorded in the Hengchun area is about $0.26 \mathrm{~g}$ ( $254 \mathrm{gals})$ at KAU046 station for the 2034 Earthquake. It is not greater than the $0.28 \mathrm{~g}$ of the code'1995, but KAU046 is the nearest strong motion station to the collapsed structure. We calculated a 5\% damping response spectra from the acceleration time histories recorded at KAU046. The results are plotted in Fig. 13 together with the corresponding design spectra in the same figure for comparison. From the observed spectral accelerations of 2026 earthquakes (Fig. 13a), the observed response spectra fall below the corresponding design spectra of the code'1995 and code'2005 in 2500 years return period, except for the EW component at the period around $1 \sim 2$ seconds, which has a larger response. Considering that it is typical for

Table 2. Design spectra in the Hengchun, Pingtung area for class 2 sites (The Committee for Architecture Technique 2005).

\begin{tabular}{rccc}
\hline Year & EPA & $\mathbf{S}_{\text {as }}$ & $\mathbf{S}_{\text {al }}$ \\
\hline 475 & $0.22 \mathrm{~g}$ & $0.55 \mathrm{~g}$ & $0.45 \mathrm{~g}$ \\
2500 & $0.28 \mathrm{~g}$ & $0.7 \mathrm{~g}$ & $0.52 \mathrm{~g}$ \\
\hline
\end{tabular}

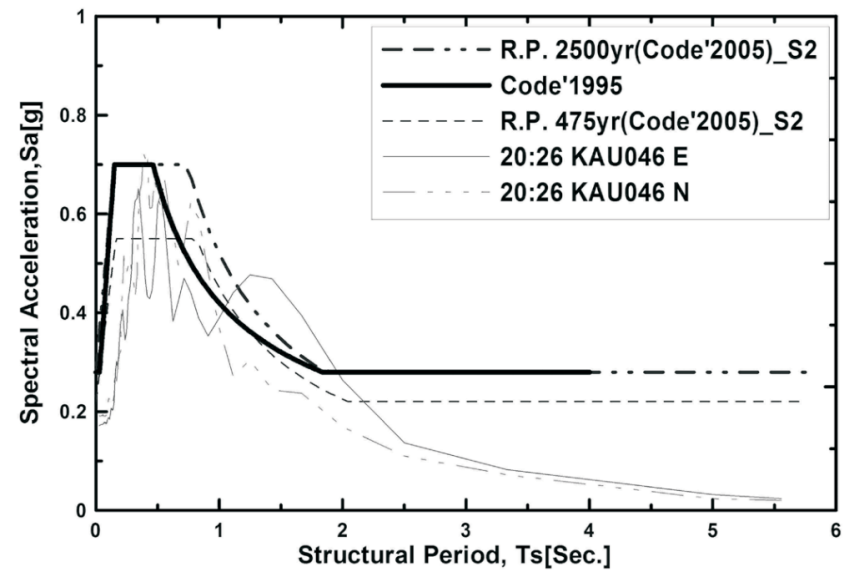

periods of $1 \sim 2$ seconds to correspond to high rise buildings greater than 10 stories, then the low-rise building collapses in the Hengchun area may not be directly due to the strong shaking of the 2026 Earthquake. For the 2034 Earthquake, except for the NS component having a larger response at around $1 \sim 2$ seconds, the observed spectral accelerations at both components are already greater than the design spectrum at less than 1 second. The damage survey also shows that the building in Fig. 5a collapsed during the second earthquake.

\section{CONCLUSIONS AND DISCUSSIONS}

Two large $\mathrm{M}_{\mathrm{L}} 7.0$ earthquakes occurred on 26 December 2006 in the offshore areas of Hengchun in Pingtung County. According to the CWB records, there have never been earthquakes of such large magnitude recorded in that area. The Pingtung Earthquake Doublet caused 2 deaths, 42 injuries ( 2 deaths and 38 injuries in Pingtung County, 3 injuries in Kaohsiung County and 1 injury in Kaohsiung City), 3 houses to collapse, and 12 fires (10 in Kaohsiung City and 2 in Pingtung County). Liquefaction occurred in the Nanwan area due to local soil back-fill problem. The earthquakes also caused massive failures of major submarine fiber-optic communication cables in the offshore areas of Hengchun, resulting in severe disruption of international telephone and Internet connections. It is still hard to assess the economic losses caused by these earthquakes.

As for response spectra, we calculated a 5\% damping response spectra from the records obtained near where the buildings collapsed. We further compared the observed response spectra with corresponding design spectra at the Hengchun, Pingtung area. With the exception that the NS component exceeded the design spectra at periods around 1 $\sim 2$ seconds, all other observed response spectra were below the design spectra for other periods of the 2026 Earthquake.

Fig. 13. Observed 5\% damping spectral acceleration at KAU046 station of the Pingtung Doublet earthquake. The design spectra of the building code in the Hengchun, Pingtung area for site class 2 also shown in the figure. 
The spectra of $1 \sim 2$ seconds only correspond to high-rise building response. This shows that the low-rise building collapse in the Hengchun area was due to the strong shaking of the 2034 Earthquake at periods less than 1 second. Furthermore, there is also possibility that the building collapse was due to the remodeling.

A total of 467 and 508 accelerographs were triggered by the 2026 and 2034 Earthquakes, respectively. The recorded PGA values generally agree with the expected values calculated from the attenuation relations for Taiwan area (using the coefficients in Table 1). Moreover, the distribution patterns of observed PGA values are also consistent except some differences with those of expected PGA values calculated based on existing ground motion prediction models. Due to the predictive models usefulness at estimating a potential shakemap for peak ground acceleration, we can use it as an early-stage reference for loss estimation and emergency response immediately after receiving the earthquake source parameters from the CWB. This will help with seismic hazard mitigation work.

Acknowledgements We would like to thank the Central Weather Bureau, Taiwan for providing the strong motion data. Special thanks are to Prof. Tien-Chien Chen, Dept. of Soil and Water Conservation, National Pingtung University of Science and Technology for providing the photos of the Figs. 5a, b, d, and 8a. We also wish to thank Prof. T. L. Teng and an anonymous reviewer for their valuable comments on the article. This study was supported by the Taiwan Earthquake Research Center (TEC) funded through National Science Council (NSC) with grant number NSC952745-M-008-003. The TEC contribution number for this article is 00034 .

\section{REFERENCES}

Campbell, K. W., 1981: Near-source attenuation of peak horizontal acceleration. Bull. Seismol. Soc. Am., 71, 20392070 .

Campbell, K. W., 1997: Empirical near-source attenuation relationships for horizontal and vertical components of peak acceleration, peak ground velocity, and pseudo-absolute acceleration response spectra. Seismol. Res. Lett., 68, 154-179.

Ho, C. S., 1986: An introduction to the geology of Taiwan - Explanatory text of the geologic map of Taiwan, Central Geological Survey, MOEA, 164 pp.

Hsu, S. K. and MACHO Working Group, 2007: Tectonic and oceanic background of the MACHO site, Abstract and
Presentations of the Workshop of the MACHO project: New earthquake and tsunami observation and expectation in Taiwan, Nov. 16-17, 921 Earthquake Museum of Taiwan.

Jean, W. Y., 2001: Seismic hazard analysis considering characteristic earthquake and site effect, National Center for Research on Earthquake Engineering Report, NCREE-01036. (in Chinese)

Jean, W. Y., Y. W. Chang, and C. H. Loh, 2003: Early estimation procedure of seismic hazard for major earthquake, Proceedings of the Joint NCREE/JRC Workshop International Collaboration on Earthquake Disaster Mitigation Research, Taipei, Taiwan, 435-440.

Jean, W. Y., Y. W. Chang, K. L. Wen, and C. H. Loh, 2006: Early estimation of seismic hazard for strong earthquakes in Taiwan. Nat. Hazards, 37, 39-53.

Kuo, K. W., T. C. Shin, and K. L. Wen, 1995: Taiwan strong motion instrumentation program (TSMIP) and preliminary analysis of site effects in Taipei basin from strong motion data. In: Cheng, F. Y. and M. S. Sheu (Eds.), Urban Disaster Mitigation: The Role of Engineering and Technology, Elsevier Science Ltd., 47-62.

Lin, C. H., 2002: Active continental subduction and crustal exhumation: The Taiwan orogeny. Terr. Nova, 14, 281-287

Liu, K. S., T. C. Shin, and Y. B. Tsai, 1999: A free-field strong motion network in Taiwan: TSMIP. Terr. Atmos. Ocean. Sci., 10, 31-50.

Pelletier, B. and J. F. Stephan, 1986: Middle Miocene subduction and late Miocene beginning of collision registered in the Hengchun Peninsula: Geodynamic implication for the evolution of Taiwan. Tectonophysics, 125, 133-160.

The Committee for Architecture Technique, 1995: The building seismic design code, Ministry of the Interior, ROC.

The Committee for Architecture Technique, 2005: The building seismic design code, Ministry of the Interior, ROC.

Tsai, Y. B., T. L. Teng, J. M. Chiu, and H. L. Liu, 1977: Tectonic implications of the seismicity in the Taiwan region. Mem. Geol. Soc. China, 2, 13-41.

Tsan, S. F., 1974a: The Kenting Formation, a note on Hengchen peninsula stratigraphy. Proc. Geol. Soc. China, 17, 131-134.

Tsan, S. F., 1974b: Stratigraphy and structure of the Hengchun peninsula, with special reference to a Miocene olistostrome. Bull. Geol. Surv. Taiwan, 24, 107-108.

Wen, K. L., Y. W. Chang, and W. Y. Jean, 2006: Seismic potential estimation of the Meishan fault, Symposium for Centenary of Meishan earthquake, Chung Cheng University, March 16 18.

Wu, F. T., 1978: Recent tectonics of Taiwan. J. Phys. Earth, 2(Suppl.), S265-299. 